\title{
The role of a dam in a water management system in Italy: physical and economic implications
}

\author{
N. Marchettini, N. Patrizi, F. M. Pulselli \& E. Tiezzi \\ Department of Chemistry, University of Siena, Italy
}

\begin{abstract}
On $4^{\text {th }}$ November 1966 a flood hit the city of Florence, with a water discharge from Arno River of $4200 \mathrm{~m}^{3} / \mathrm{s}$ causing death and destruction. To safeguard Florence against any such future events, the Bilancino dam was built along the Sieve River, the main right tributary of the Arno River. The dam is also an important element for the water management of the Florence area. The artificial basin is $5 \mathrm{~km}^{2}$ wide and represents a water reservoir of $8.4 \times 10^{7} \mathrm{~m}^{3}$. The paper presents the results of the emergy evaluation of the Bilancino's artificial basin and its role. The emergy evaluation is an environmental accounting method that converts all different inputs, inflows of energy and matter into a system or a production process, to a common denominator, the equivalent solar energy. The emergy represents the quantity of solar energy that was used, directly or indirectly, to obtain a good or service. In other words, emergy accounting enables to "memorize" all the energy that was necessary in the past to obtain a flow or a product that is available today. The environmental costs of the Bilancino's dam, which creates the basin, as well as the economic benefits of its presence are evaluated from an emergy point of view. In order to calculate the emergy of the dam, the resource flows constituting it have been considered: materials used to build the dam (rockfill diabase, rockfill limestone, gravel, sandstone and clay) and construction and annual management costs. Environmental costs like sediment loss and the loss of organic matter (land) have also been taken into consideration. The emergy investment for the construction and maintenance of the dam is finally compared with the emergy estimate of a future incidental flooding.
\end{abstract}

Keywords: emergy, water management, dam, watershed, environmental costs. 


\section{Introduction}

By definition, water is a unique and vital resource, for which there is no substitute. Water plays a central role in the whole biosphere's life and can be considered as a bloodstream of the biosphere [1]. Water also determines the sustainability of living systems as it is essential for every biological aspect and for the survival of mankind [2]. Water is the most precious resource in the whole planet and mankind has tried to control and manage water resources since the beginning of agriculture and the creation of cities [3, 4].

Managing water in a sustainable way means to be conscious that water has a strategic role both for present and future generations [2, 5].

However, water can become a problem. A river needs to be properly managed, otherwise, it could cause disasters like damaging floods. Many kinds of facilities are built by humans to control water such as dams, channeling of rivers or adjustments of the level of rivers beds.

As reported in Morozzi [6], the city of Florence has flooded 56 times since the $12^{\text {th }}$ century. The most catastrophic of all these floods in the city of Florence occurred on $4^{\text {th }}$ November 1966 when an exceptional flash flood hit the city and its inhabitants causing destruction and death. The Arno River discharged into the city an enormous quantity of water, a portion of the city was flooded and the water level reached $5.20 \mathrm{~m}$ in some points. This flood was produced by an exceptional meteorological event between the $3^{\text {rd }}$ and $5^{\text {th }}$ November 1966 , which hit Italy. In Tuscany, the total rainfall was higher than $200 \mathrm{~mm}$ and the total rainfall during the month of October exceeded the average rainfall by $150-300 \%$ [7].

After this dramatic flood many scientists and technicians highlighted the necessity to regulate the flow of the Arno River, implying also the need to manage and regulate the flows of its tributaries, the main one being the Sieve River. The regime of the Sieve River is very similar to that of a torrent as it alternates low and high flows characterized by several hundreds of $\mathrm{m}^{3}$ per second. On $4^{\text {th }}$ November 1966 the flow of the Sieve River reached $1340 \mathrm{~m}^{3}$ per second, 24\% higher than the recorded maximum [7, 8]. As a consequence, Bilancino's dam was built to both regulate the regime of Sieve River (thus to manage as best as possible the Arno River watershed) and have a water reservoir.

This paper presents the results of the emergy analysis [9, 10] of the lake and dam of Bilancino. An environmental accounting system providing a measure of both environmental costs and economic benefits of the presence of Bilancino Lake and its dam is presented.

The application of emergy to the Bilancino dam is useful to measure the contribution of human inputs and the ecosystem's effort to manage the Arno River watershed. A cost benefit analysis comparing the investment and damage due to a possible flooding is also presented in emergy terms. 


\section{Materials and methods}

\subsection{Study area}

The area under study is the Arno River watershed, located in Tuscany (Italy) (Figure 1). The river is $241 \mathrm{~km}$ long and its catchment area is about $8,830 \mathrm{~km}^{2}$ [7]. The Bilancino Lake is located in the Sieve River watershed, a subsystem of the Arno watershed. In fact, the Sieve River is the main right tributary of Arno River and influences its regime. Thus, in order to regulate the regime of Arno River, Bilancino Lake was created by means of a dam along the Sieve River.

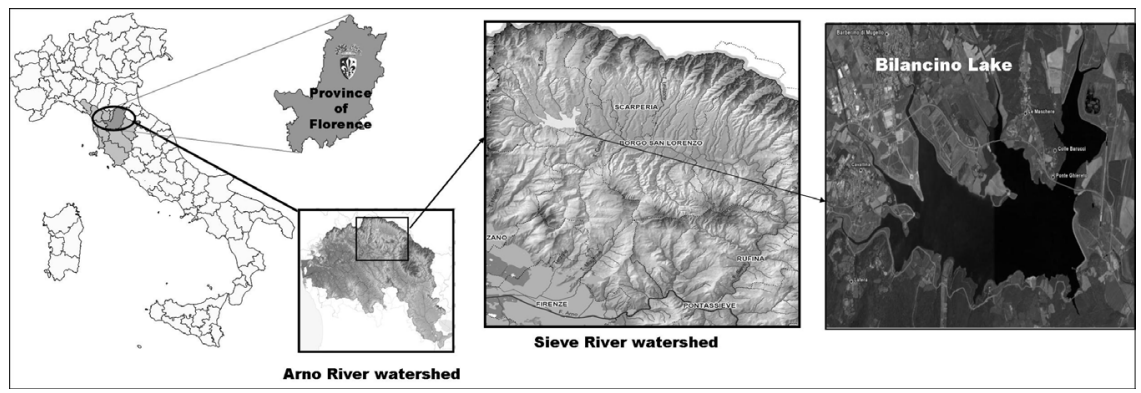

Figure 1: Geographical location of the study area.

The lake is located in the area of an ancient Pleistocene lake which was drained by the Etruscans. The area of the current artificial basin is $5 \mathrm{~km}^{2}$ and represents a water reservoir of $84 \times 10^{6} \mathrm{~m}^{3}$ [11].

The Bilancino dam is mainly made of natural and local materials, such as dibasic rockfill, limestone rockfill, gravel, sandstone and clay. The amount of reinforced concrete is negligible and was not considered.

Bilancino Lake plays a central role for the water management of the entire watershed of the Arno River. In fact, it was built to:

a. integrate the minimum flow of the Arno River of $8 \mathrm{~m}^{3} / \mathrm{sec}$ to satisfy the water needs of both the towns in the Sieve valley and the city of Florence.

b. decrease the water pollution downstream of the City of Florence and maintain the flow of Arno River at $4 \mathrm{~m}^{3} / \mathrm{sec}$ along its civic stretch.

The most important consequence derived from the construction of Bilancino Lake has been the noticeable flood control. Finally, the Lake was found to improve tourism in the Mugello Area.

\subsection{Emergy evaluation}

Emergy was introduced by H. T. Odum during the 1980s as a tool of environmental (but not only environmental) accounting [10]. On the basis of a thermodynamic hierarchy of energy, starting from solar energy, Odum's research has provided a measure of the environmental work necessary to generate an item or a flow. 
Emergy is defined as the quantity of solar energy directly or indirectly necessary to support a given system and its level of organization. The emergy of all inputs to a system is calculated in terms of solar emjoules (sej) by means of suitable conversion factors called transformities (expressed in sej/J), or specific emergy (expressed in sej/g or other units) [9, 10, 12]. Emergy represents a measure able to evaluate the convergence of several inputs to a system on a common basis. In this way it is possible to consider a system's economic and environmental aspects at the same time, expressing all inputs and outputs in the same terms: equivalent solar energy. The total emergy, Em, of a product produced by a process is the sum of energy content (Ei) of the $i$ inputs supporting the process multiplied by their transformities $\left(\operatorname{Tr}_{\mathrm{i}}\right)$ :

$$
\left.E m=\left(E_{1} x \operatorname{Tr}_{1}\right)+\left(E_{2} x \operatorname{Tr}_{2}\right)\right)+\ldots+\left(E_{n} x T r_{n}\right)=\sum_{i=1}^{n} E_{i} x T r_{i}
$$

Moreover, emergy can be considered as an energy memory, or the memory of all the solar energy necessary to support a system, including the energy input upstream of transformation processes in the system and those involved in all steps of the processes [13, 14].

An energy diagram is usually used to represent all the elements and interactions characterizing a given system. The interactions, in particular, are represented by arrows that correspond to the flows of energy and matter supporting the system. An energy diagram (Figure 2) was built in order to identify all flows of energy and matter involved [15]. The boundaries of the

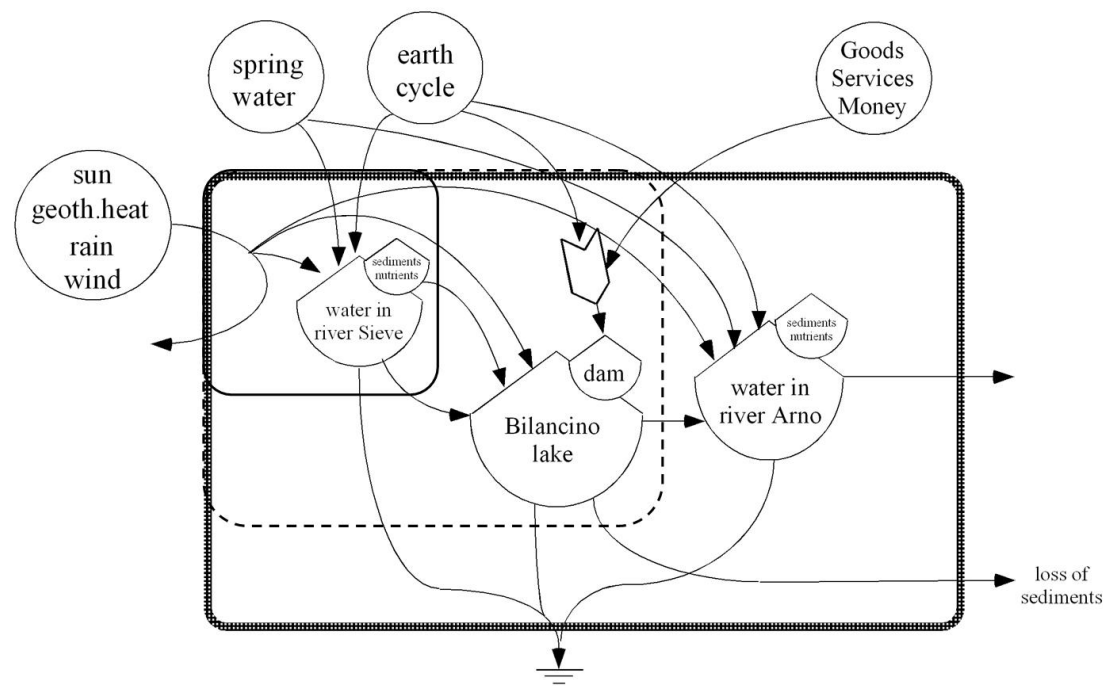

Figure 2: Energy diagram of the system under study. The bold box represents the boundaries of the subsystem upstream of Bilancino dam; the dotted box represents the boundaries of the subsystem downstream of Bilancino dam. 
analyzed system coincide with the Arno River watershed and are represented by the larger rectangle.

As shown in Figure 2, the water in the Rivers and the Lake is created by the interaction among renewable resources supporting water cycle. The dam is created by the interaction between renewable and non-renewable resources (goods and services) that come from outside the system.

The diagram provides an overview of the system and its main components. The analysis was carried out with the purpose of determining an environmental value of water along the river in emergy terms and evaluating the contribution of human infrastructure (the dam) to water management.

The emergy analysis can be used to evaluate the impact of facilities necessary to manage water along a river (like dams or river diversions) as reported in literature [16-18].

\section{Results and discussion}

The calculation of the environmental value of water upstream of Bilancino dam along the Sieve River is represented in Figure 2 by the black box. Upstream of the dam, the flows considered for the natural water production as inputs were: sun, rain, geothermal heat and basic flow (as a proxy of spring water). The dotted box presented in Figure 2 relates to the emergy calculation downstream of the Bilancino dam. Together with the flows previously identified, building materials and the costs (construction and maintenance) of the dam were also accounted in the analysis. Since sunlight and rain are coproducts [10], only the main one (rain) was counted. All raw data was collected from official authorities managing the Sieve River (Autorità di Bacino del Fiume Arno, Regione Toscana, ARSIA, Publiacqua S.p.a.). The outputs of the subsystems (upstream and downstream of Bilancino Lake) are represented by the amount of water that flows every year in and out the Bilancino Lake. Raw data (mass quantities) has been reported in the two tables of emergy calculation (tables 1 and 2). All data have been than processed thorough the relative emergy per unit and expressed in terms of solar emergy joules. All emergy tables include six columns. The first column indicates the names of items considered, the second the amount expressed in different units of measurement (shown in the third column). In the fifth column are reported the emergy per unit used (their relative reference are reported in the

Table 1: Calculation of specific emergy of water upstream of Bilancino dam.

\begin{tabular}{|c|c|c|c|c|c|}
\hline & & & & Specific Emergy & Emergy \\
\hline Item & Input & Unit & Reference & (sej/unit) & (sej/year) \\
\hline 1 Sunlight & $1.92 \times 10^{17}$ & $\mathrm{~J}$ & [19] & 1 & $1.92 \times 10^{17}$ \\
\hline 2 Rain & $5.29 \times 10^{13}$ & $\mathrm{~g}$ & {$[20]$} & $1.45 \times 10^{5}$ & $7.67 \times 10^{18}$ \\
\hline 3 Geothermal heat & $1.06 \times 10^{14}$ & $\mathrm{~J}$ & {$[20]$} & $1.20 \times 10^{4}$ & $1.28 \times 10^{18}$ \\
\hline 4 Spring water & $1.02 \times 10^{12}$ & $\mathrm{~g}$ & {$[21]$} & $3.40 \times 10^{5}$ & $3.48 \times 10^{17}$ \\
\hline Total emergy & & & & & $9.30 \times 10^{18}$ \\
\hline 5 Surface water flow upstream of Bilancino & $4.06 \times 10^{13}$ & $\mathrm{~g}$ & this study & $2.29 \times 10^{5}$ & \\
\hline
\end{tabular}


Table 2: Calculation of specific emergy of water downstream of Bilancino dam.

\begin{tabular}{|c|c|c|c|c|c|c|}
\hline & & & & & Specific Emergy & Emergy \\
\hline \multicolumn{2}{|r|}{ Item } & Input & Unit & Reference & (sej/unit) & (sej/year) \\
\hline \multicolumn{2}{|c|}{1 Sunlight } & $6.334 \times 10^{17}$ & $\mathrm{~J}$ & [19] & 1 & $6.33 \times 10^{17}$ \\
\hline \multicolumn{2}{|c|}{2 Rain } & $1.42 \times 10^{14}$ & $\mathrm{~g}$ & {$[20]$} & $1.45 \times 10^{5}$ & $2.06 \times 10^{19}$ \\
\hline \multicolumn{2}{|r|}{3 Geothermal heat } & $3.49 \times 10^{14}$ & $\mathrm{~J}$ & {$[20]$} & $1.20 \times 10^{4}$ & $4.19 \times 10^{18}$ \\
\hline \multicolumn{2}{|r|}{4 Spring water } & $3.36 \times 10^{12}$ & $\mathrm{~g}$ & [121] & $3.40 \times 10^{5}$ & $1.14 \times 10^{18}$ \\
\hline \multicolumn{7}{|c|}{6 Dam } \\
\hline \multicolumn{2}{|r|}{ Diabasic rockfill } & $4.90 \times 10^{9}$ & $\mathrm{~g}$ & {$[22]$} & $9.50 \times 10^{9}$ & $4.65 \times 10^{19}$ \\
\hline \multicolumn{2}{|r|}{ Limestone } & $9.34 \times 10^{9}$ & $\mathrm{~g}$ & {$[22]$} & $9.50 \times 10^{9}$ & $8.87 \times 10^{19}$ \\
\hline \multicolumn{2}{|r|}{ Gravel } & $2.58 \times 10^{9}$ & $\mathrm{~g}$ & {$[10]$} & $1.68 \times 10^{9}$ & $4.33 \times 10^{18}$ \\
\hline \multirow{2}{*}{$\begin{array}{c}6 \mathrm{~d} \\
6 \mathrm{e}\end{array}$} & Sand & $2.85 \times 10^{9}$ & $\mathrm{~g}$ & {$[10]$} & $1.68 \times 10^{9}$ & $4.79 \times 10^{18}$ \\
\hline & Clay & $4.63 \times 10^{9}$ & $\mathrm{~g}$ & {$[10]$} & $4.10 \times 10^{9}$ & $1.90 \times 10^{19}$ \\
\hline \multicolumn{2}{|r|}{7 Costs (building, maintenance) } & $2.10 \times 10^{6}$ & $€$ & {$[23]$} & $1.40 \times 10^{12}$ & $2.94 \times 10^{18}$ \\
\hline \multicolumn{2}{|r|}{ Total emergy } & & & & & $1.92 \times 10^{20}$ \\
\hline \multicolumn{2}{|r|}{5 Surface water flow downstream of Bilancino } & $1.36 \times 10^{14}$ & $\mathrm{~g}$ & this study & $1.42 \times 10^{6}$ & \\
\hline
\end{tabular}

fourth column), as well as the specific emergy of water calculated in each of the two points. Finally, in the last column, values are expressed in terms of emergy by multiplying the amount (second column) by its emergy per unit (fifth column).

The value of water upstream of Bilancino is $2,29 \times 10^{5} \mathrm{sej} / \mathrm{g}$ (Table 1 ). Downstream of the dam this value is $1,42 \times 10^{6} \mathrm{sej} / \mathrm{g}$ (6 times greater). This is obviously due to the presence of the infrastructure. However, along the watershed the weight of the dam per unit water tends to decrease progressively, because the emergy content of the dam is distributed over a larger area and a greater amount of water, especially if we consider the entire Arno watershed (the target of the investment).

\subsection{Comparison of emergy and economic values}

Emergy evaluation enables all flows of energy and matter to be converted into flows of solar energy equivalent through the transformities. Also monetary flows can be converted into equivalent solar energy flows through a particular coefficient called emergy money ratio (EMR). It corresponds to the ratio between the emergy flow supporting an economic system (e.g. a nation) and the economic product of the same system (e.g. the GDP of that nation). Namely, the EMR represents the amount of emergy contained in $1 €$ of economic output. It has been used to convert the economic costs (building and maintenance) of the dam into emergy flows. In order to evaluate the whole cost of the dam, beside the inputs of material and construction and maintenance costs, other two environmental costs related to the presence of the dam are accounted for: the loss of sediments (the dam interrupts the sedimentary flow) and the loss of organic matter (the Lake of Bilancino occupies lands that can be potentially cultivated). All these (economic and environmental) costs are equal to $4.35 \times 10^{20} \mathrm{sej} / \mathrm{year}$ (Table 3). The company that manage the Arno River watershed, Autorità di Bacino del Fiume Arno, estimated the economic costs of a future flood similar to that of $4^{\text {th }}$ November 1966: it can be about 20 billions of Euro (translated into emergy by means of the EMR it is equal to $2.80 \times 10^{22}$ ). In table 3 we compared this supposed economic damage with the environmental costs of Bilancino dam. 
Table 3: Comparison between environmental costs of Bilancino dam and hypothetical damage.

\begin{tabular}{|c|c|c|c|c|c|}
\hline & & & & Specific Emergy & Emergy \\
\hline Item & Input & Unit & Reference & (sej/unit) & (sej/year) \\
\hline 1 Sunlight & $6.334 \times 10^{17}$ & $\mathrm{~J}$ & [17] & 1 & $6.33 \times 10^{17}$ \\
\hline 2 Rain & $1.42 \times 10^{14}$ & $\mathrm{~g}$ & [18] & $1.45 \times 10^{5}$ & $2.06 \times 10^{19}$ \\
\hline 3 Geothermal heat & $3.49 \times 10^{14}$ & $\mathrm{~J}$ & [18] & $1.20 \times 10^{4}$ & $4.19 \times 10^{18}$ \\
\hline 4 Spring water & $3.36 \times 10^{12}$ & $\mathrm{~g}$ & [19] & $3.40 \times 10^{5}$ & $1.14 \times 10^{18}$ \\
\hline \multicolumn{6}{|l|}{6 Dam } \\
\hline 6a Diabasic rockfill & $4.90 \times 10^{9}$ & g & [20] & $9.50 \times 10^{9}$ & $4.65 \times 10^{19}$ \\
\hline 6b Limestone & $9.34 \times 10^{9}$ & g & [20] & $9.50 \times 10^{9}$ & $8.87 \times 10^{19}$ \\
\hline 6c Gravel & $2.58 \times 10^{9}$ & $\mathrm{~g}$ & {$[10]$} & $1.68 \times 10^{9}$ & $4.33 \times 10^{18}$ \\
\hline 6d Sand & $2.85 \times 10^{9}$ & $\mathrm{~g}$ & [10] & $1.68 \times 10^{9}$ & $4.79 \times 10^{18}$ \\
\hline 6e Clay & $4.63 \times 10^{9}$ & $\mathrm{~g}$ & [10] & $4.10 \times 10^{9}$ & $1.90 \times 10^{19}$ \\
\hline 7 Costs (building, maintenance) & $2.10 \times 10^{6}$ & $€$ & [21] & $1.40 \times 10^{12}$ & $2.94 \times 10^{18}$ \\
\hline Total emergy & & & & & $1.92 \times 10^{20}$ \\
\hline 5 Surface water flow downstream Bilancino & $1.36 \times 10^{14}$ & $\mathrm{~g}$ & this study & $1.42 \times 10^{6}$ & \\
\hline
\end{tabular}

Comparing the total emergy cost of the dam and the emergy of the hypothetical damage, it emerges that the investment for the construction of Bilancino amounts to $1.5 \%$ of the damage.

Moreover, since Arno is the main river of Tuscany, we can compare the investment to build the dam and the hypothetical damage of a flood with Tuscan GDP, that is 95.12 billions of Euro in 2006. On the one hand, the cost of an eventual flood in the Arno watershed is about $20 \%$ of Tuscan GDP. On the other hand, the cost of the presence of the dam $\left(4.35 \times 10^{20} \mathrm{sej} / \mathrm{yr}\right.$, Table 3$)$, translated into money by means of the EMR, is 310 millions of Euro, equal to $0.33 \%$ of Tuscan GDP. This is in line with Nicholas Stern's statements on the economic costs of climate change. As reported in his Review [24], if nothing further is done to reduce emissions, the total costs of the impact of climate change will reduce the Gross Global Product by between 5\% and 20\% per year. This can be avoided by investing every year the $1 \%$ GDP.

\section{Conclusions}

This paper shows that emergy accounting it is a tool able to evaluate the role of a given infrastructure (namely a dam) considering both environmental and economic efforts necessary to its realization. Thanks to its ability to convert all inputs into the common denominator of solar energy it was possible to evaluate the human contribution to the water management together with the environmental effort to produce water. Moreover, emergy evaluation enabled one to demonstrate that the choice to invest economic resources to build the dam was a prudent decision, useful to manage water in a sustainable way and to avoid the costs of hypothetical future floods. 


\section{References}

[1] Ripl, W., Water: the bloodstream of the biosphere. Phil. Trans. R. Soc. Lond. B, 358, pp. 1921-1934, 2003.

[2] Fiorillo, F., Palestrini, A., Polidori, P., Socci, C., Modelling water policies with sustainability constraints: A dynamic accounting analysis. Ecological Economics, 63, pp. 392-402, 2007.

[3] Gleick, P.H., The changing water paradigm a look at twenty first century water resources water development. Water International, 25(1), pp. 127 $138,2000$.

[4] Serageldin, I., Water resources management: a new policy for a sustainable future. Water Resource Development, 11 (3), pp. 221-232, 1995.

[5] Helström, D., Jeppsson, U., Kärrman, E., A framework for systems analysis of sustainable water management. Environmental Impact Assessment Review, 20, pp. 311-321, 2000.

[6] Morozzi, F., Dello Stato antico e moderno dell'Arno e delle cause e de' rimedi delle sue inondazioni. Ragionamento istorico-matematico. Stecchi eds., Firenze, 1762.

[7] Caporali, E., Rinaldi, M., Casagli, N., The Arno River Floods. Giornale di Geologia Applicata, 1, pp. 177-192, 2005.

[8] ARPAT (eds.), Fiume Sieve: affluente di destra dell'Arno. Firenze, 2005.

[9] Odum, H.T., Self organization, transformity and information. Science, 242, pp. 1132-1139, 1988.

[10] Odum, H.T., Environmental accounting: emergy and environmental decision making, John Wiley \& Sons: New York, 1996.

[11] ARPAT (eds.). Invaso di Bilancino- Studio e monitoraggio della qualità delle acque. Firenze, 2005.

[12] Odum, H.T., Environment, Power and Society. Wiley: New York, 1971.

[13] Scienceman, D. M., Energy and emergy. Environmental Economics; the Analysis of a Major Interface, ed. G. Pillet, T. Murota, Roland, Leimgruber: Geneva, pp. 257-276, 1987

[14] Scienceman, D. M., The emergence of economics. Proceedings of the 33rd International Society for Social System Science, Edinburgh, Scotland (III), pp. 62-68, 1989.

[15] Odum, H.T., Ecological and general systems: an introduction to systems ecology. Revised edition, University Press of Colorado, Niwot, Colorado, pp. 6, 1994

[16] Brown M.T. \& McClanahan T.R., Emergy analysis perspectives of Thailand Mekong River dam proposal. Ecological Modelling, 91, pp.105130, 1996.

[17] Martin, J.F., Emergy evaluation of river water to marshes in the Mississippi River Delta. Ecological Engineering, 18, pp. 265-286, 2002.

[18] Kang, D. and Park, S.S., Emergy evaluation perspectives of a multipurpose dam proposal in Korea. Journal of Environmental Management, 66(3), pp. 293-306, 2002. 
[19] Odum, H.T., Emergy and biogeochemical cycles. Ecological Physical Chemistry, eds. C. Rossi and Tiezzi E., Elsevier Science Publishers: Amsterdam, pp. 25-56, 1991.

[20] Odum, H.T., Brown, M.T., Brandt Williams, S., Handbook of emergy evaluation: Folio \#1 - Introduction and Global Budget. Center for Environmental Policy, University of Florida, Gainesville, Florida, 2000.

[21] Brown, M.T. and Arding, J.E., Transformity Working Paper. Center for Wetlands, University of Florida, Gainesville, Florida, 1991.

[22] Odum, H.T., Handbook of emergy evaluation: Folio \#2 - Emergy of Global Processes. Center for Environmental Policy, University of Florida, Gainesville, Florida, 2000.

[23] Pulselli, R.M., Rustici, M. and Marchettini, N., An integrated holistic framework for regional studies: emergy based spatial analysis of the province of Cagliari. Environmental Monitoring and Assessment, 133 (1-3), pp. 1-13, 2006.

[24] Stern, N., Stern Review on the economics of climate change, Cambridge University Press, Cambridge, 2006. 